\title{
The prevalence of low back pain among nurses working in Poursina hospital in Rasht, Iran
}

\author{
Payman Asadi, Vahid Monsef Kasmaei, Seyyed Mahdi Zia Ziabari, Behzad Zohrevandi*
}

Road Trauma Research Center, Guilan University of Medical Sciences, Rasht, Iran

\author{
Received: 2 June 2015 \\ Accepted: 24 June 2015 \\ Published online: 17 October 2015 \\ *Corresponding author: Behzad \\ Zohrevandi, Road Trauma Research \\ Center, Guilan University of Medical \\ Sciences, Rasht, Iran. \\ Tel: 09188523847, \\ Fax: 01333338373 \\ Email: bzohrevandi@yahoo.com \\ Competing interests: None. \\ Funding information: There were \\ no financial resources regarding this \\ study. \\ Citation: Asadi P, Monsef Kasmaei \\ V, Zia Ziabari SM, Zohrevandi B. The \\ prevalence of low back pain among \\ nurses working in Poursina hospital \\ in Rasht, Iran. Journal of Emergency \\ Practice and Trauma 2016; 2(1): 11- \\ 15. doi: $10.15171 /$ jept.2015.01.
}

\begin{abstract}
Objective: Low back pain is the most common skeletal disorder worldwide that $50 \%$ to $80 \%$ of people experience it at least once in their lifetime. Physical and psychological factors in the work environment can relatively contribute to low back pain. In this study, we examined the prevalence of low back pain and influential factors in its development among nursing staff.

Methods: In this cross-sectional study we assessed the prevalence of low back pain among nurses working in Poursina hospital, Rasht, Iran, during March and April 2012. Demographic data and information on the status of skeletal pain, as well as, associated factors were collected using a pre-designed check list. Data were analyzed using SPSS version 16.

Results: A total of 350 nurses with a mean age of $32.00 \pm 8.24$ years (minimum 22 and maximum 56 years) were studied ( $90.3 \%$ female). 246 participants $(70.3 \%)$ had a history of low back pain. There was no significant difference between gender and the incidence of low back pain, $(P=0.286)$. 96 participants $(27.4 \%)$ aged 27 to 31 had the highest rate of low back pain and 11 participants (3.1\%) aged 52 to 56 were the least frequent age group. Low back pain significantly differed by age $(P=0.001)$, body mass index (BMI) $(P=0.222)$, and physical activity $(P=0.050)$.

Conclusion: The results of this study showed a prevalence of $70 \%$ for low back pain among nurses working in Poursina hospital in Rasht, in Gilan province. Age, BMI, and physical activity were significantly associated with the prevalence of low back pain. However, gender, occupation, marital status, smoking, family history, frequency of lifting heavy things, work experience, and workplace did not show a significant relationship.

Keywords: Low back pain, Nurses, Prevalence, Risk factors
\end{abstract}

\section{Introduction}

Low back pain as the most common skeletal disorder worldwide is experienced by $50 \%$ to $80 \%$ of people at least once in their lifetime $(1,2)$. In addition to upper respiratory system diseases and headache, low back pain is the third leading cause of physicians' visits (3). Although many factors are involved in causing low back pain, but some jobs can increase the risk. In other words, physical and psychological factors in the work environment can somehow play a role in causing low back pain (4). In jobs such as nursing, driving, and laboring, due to frequent changes in posture, lifting heavy loads and bending, the prevalence of low back pain is more than other jobs $(3,5)$. Low back pain is identified as one of the most common complaints in nurses with an estimation of $38 \%-67 \%$ in the American nurses, $73 \%-76 \%$ in German nurses, and $9.38 \%$ in nurses in Hong Kong (6-10). Low back pain can cause occupational disabilities, increased cost of care and treatment, loss of productivity, and absence from work $(3,11)$. Gender is an influential factor in this area, however, the impact of factors such as age, duration of activity and smoking cannot be disregarded (12-15). Although the cause of low back pain can be detected through patient complaints, clinical examinations, laboratory tests and medical imaging, but the main reason behind it is somewhat difficult to detect. Therefore to reduce the incidence of back pain, risk factors should be identified and preventive policies should be considered. This is significantly important not only for the treatment and medical costs that this incidence place on the health care system but also due to the critical role of nurses in public health. Thus, in this study, we examined the prevalence of low back pain and influential factors in its development among nursing staff in 2012.

\section{Methods}

This was a cross-sectional study to assess the prevalence of low back pain among nurses working in Poursina hospital, Gilan, Iran, during March and April 2012. Based 
on the census method of data collection, all nursing staff including nurses, licensed nursing assistants, and nursing assistants entered the study. Demographic data and information about work experience, a history of low back pain, body mass index, marital status, workplace, and treatments performed (medication, physiotherapy, bed rest), history of physical exercise, smoking history, family history of low back pain, history of musculoskeletal disorders, parity, number of children, duration of time devoted to doing housework, frequency of patient relocation on a stretcher and vice versa, the frequency of lifting objects weighing more than $3 \mathrm{~kg}$, and depression were completed using a pre-designed checklist. Individuals with known congenital skeletal abnormalities were excluded from the study. To complete a more accurate list, in coordination with the hospital director, nursing services manager, and training supervisor, more detailed nurses' information were extracted. Finally, collected data were analyzed using SPSS version 16 software through chi-square test. A significant level of $P<0.05$ was considered.

\section{Definitions}

Physical activity: at least 150 minutes of physical activity per week that leads to increased heart rate.

Body mass index (BMI): A person's weight in kilograms divided by the square of height in meters. According to the value obtained, subjects are divided into 4 groups, underweight (BMI less than 18), normal (BMI between 18.5 and 24.99), overweight (BMI between 25 and 30) and, obese (BMI more than 30).

\section{Results}

A total of 350 nurses with the mean age of $32.00 \pm 8.24$ years (minimum 22 and maximum 56 years) were studied (90.3\% female): 306 nurses (87.4\%), 25 licensed nursing assistants (7.1\%), and 19 nursing assistants (5.4\%). A total of 246 participants $(70.3 \%)$ had a history of back pain, while 104 (29.70\%) had no history of low back pain. Table 1 shows background information of patients. There was no significant difference $(P=0.286)$ between gender and the incidence of low back pain. Ninety-six participants (27.4\%) aged 27 to 31 had the highest rate of low back pain and 11 participants $(3.1 \%)$ aged 52 to 56 were the least frequent age group. Table 2 shows the frequency of low back pain according to sex, age, BMI, physical activity, smoking, family history, frequency of lifting heavy things, work experience, and workplace. A significant difference was observed between age and the history of low back pain $(P<0.001)$. The mean BMI was $24.10 \pm 4.74$ (minimum 16.5 and maximum 66). The highest rates of low back pain were seen in people with a BMI of 19-24.99 (49.2\%) and the lowest in individuals with a BMI of less than 18.5 (4.5\%). There was no significant difference between the history of low back pain and physical exercise $(P=0.050)$.Treatment method included bed rest $(34.1 \%)$, combination therapy (30.9\%), use of medication (22\%),
Table 1. Background information of the participants

\begin{tabular}{lcc}
\hline Information & Female (\%) & Male (\%) \\
\hline Gender & $316(90.3)$ & $34(9.7)$ \\
Occupation & & \\
$\quad$ Nurse & $289(94.4)$ & $17(5.6)$ \\
Licensed nursing assistant & $17(68)$ & $8(32)$ \\
Nursing assistant & $10(52.6)$ & $9(47.4)$ \\
Physical activity & & \\
Positive & $122(87.1)$ & $18(12.9)$ \\
Negative & $194(92.4)$ & $16(6.7)$ \\
No. of children & & \\
0 & $166(98.2)$ & $3(1.8)$ \\
1 & $80(87)$ & $12(13)$ \\
2 & $52(77.6)$ & $15(22.4)$ \\
3 & $13(76.5)$ & $4(23.5)$ \\
4 & $5(100)$ & $0(0)$ \\
\hline
\end{tabular}

and physiotherapy $(3.7 \%)$ and $9.3 \%$ of the cases received no treatment. The mean number of lifting heavy things by nursing staff had no significant association with low back pain $(P=0.25)$. The highest frequency of pain was related to the group with less than 5 years of work experience including 120 patients (34.3\%) and subjects with 20-25 years of work experience had the minimum rate, including 21 patients (6\%). There was no significant relationship between work experience and a history of low back pain $(P=0.08)$. Also, no significant relationship was found between the prevalence of low back pain and workplace $(P=0.606)$.

\section{Discussion}

Results of this study showed a prevalence of $70 \%$ for low back pain among nurses working in Poursina hospital, Rasht, Gilan province. Age, BMI, and physical activity were significantly associated with the prevalence of low back pain. Yet, the relationship between gender, occupation, marital status, smoking, family history, frequency of lifting heavy things, work experience, and workplace was not significantly confirmed. Low back pain is a common problem in which $50 \%$ to $80 \%$ of people experience it during their lifetime $(1,2)$. The prevalence of low back pain varies according to occupations. Ramazani Badr et al (16) reported a prevalence of $52.7 \%$ in nursing staff. The cumulative incidence of back pain was assessed at $57.7 \%$ and the annual incidence rate was at $1.5 \%$ in Bejia et al (17) investigation. A higher prevalence of low back pain (73\%-76\%) was reported in the study of Maul et al (6). This difference in prevalence in different studies may be due to differences in occupational factors, different definitions of back pain or back pain prevalence rate in different time periods $(6,16,17)$. Heavy physical activities such as moving and lifting patients are the most important risk factors for low back pain among nurses. Most research- 
Table 2. Prevalence of low back pain according to gender, age, BMI, occupation, amount of exercise, smoking, family history, frequency of lifting heavy things, work history, marital status, and workplace

\begin{tabular}{|c|c|c|c|}
\hline Variable & $\begin{array}{c}\text { Subjects with a history of back } \\
\text { pain, No. (\%) }\end{array}$ & $\begin{array}{c}\text { Subjects without a history of } \\
\text { back pain, No. (\%) }\end{array}$ & $P$ \\
\hline Sex & & & 0.286 \\
\hline Female & $224(91.1)$ & $92(88.5)$ & \\
\hline Male & $22(8.9)$ & $12(11.5)$ & \\
\hline Age group (y) & & & 0.001 \\
\hline $22-26$ & $32(13)$ & $34(32.7)$ & \\
\hline $27-31$ & $66(26.8)$ & $30(28.8)$ & \\
\hline $32-36$ & $56(22.8)$ & $18(16.3)$ & \\
\hline $37-41$ & $33(13.4)$ & $12(11.5)$ & \\
\hline $42-46$ & $24(9.8)$ & $5(4.8)$ & \\
\hline $47-51$ & $25(10.2)$ & $5(4.8)$ & \\
\hline $52-56$ & $10(4.1)$ & $1(1)$ & \\
\hline BMI & & & 0.022 \\
\hline$<18.5$ & $11(4.5)$ & $9(8.7)$ & \\
\hline $19-24.99$ & $121(49.2)$ & $61(58.7)$ & \\
\hline $25-30$ & $79(32.1)$ & $29(27.9)$ & \\
\hline$\geq 30$ & $35(14.2)$ & $5(4.8)$ & \\
\hline Occupation & & & 0.489 \\
\hline Nurse & $217(88.2)$ & $89(85.6)$ & \\
\hline Licensed nursing assistant & $15(6.1)$ & $10(9.6)$ & \\
\hline Nursing assistant & $14(5.7)$ & $5(4.8)$ & \\
\hline Marital status & & & 0.804 \\
\hline Single & $73(29.7)$ & $33(31.7)$ & \\
\hline Married & $170(96.1)$ & $69(66.3)$ & \\
\hline Widow/widower & $3(1.2)$ & $2(1.9)$ & \\
\hline Physical activity & & & 0.05 \\
\hline Yes & $91(37)$ & $49(47.1)$ & \\
\hline No & $15(63)$ & $55(52.9)$ & \\
\hline Smoking & & & 0.187 \\
\hline Yes & $4(1.6)$ & $4(3.8)$ & \\
\hline No & $242(98.4)$ & $100(96.2)$ & \\
\hline A history of low back pain, according to family history & & & 0.23 \\
\hline Yes & $144(58.5)$ & $66(63.5)$ & \\
\hline No & $102(41.5)$ & $38(36.5)$ & \\
\hline The frequency of lifting heavy things & & & 0.25 \\
\hline Very high (6 times or more per shift) & $95(38.6)$ & $26(25)$ & \\
\hline High (4-5 times per shift) & $62(25.2)$ & $24(23.1)$ & \\
\hline Moderate (2-3 times per shift) & $36(14.6)$ & $18(17.3)$ & \\
\hline Low (0 to 1 time per shift) & $53(21.5)$ & $36(34.6)$ & \\
\hline Working experience (year) & & & 0.08 \\
\hline $5<$ & $69(28)$ & $51(49)$ & \\
\hline $5-10$ & $73(29.7)$ & $24(23.1)$ & \\
\hline $10-15$ & $40(16.3)$ & $11(10.6)$ & \\
\hline $15-20$ & $30(12.2)$ & $11(10.6)$ & \\
\hline $20-25$ & $16(6.5)$ & $4(3.8)$ & \\
\hline$>25$ & $18(7.3)$ & $3(2.9)$ & \\
\hline Work place & & & 0.606 \\
\hline Emergency department 1 & $22(8.9)$ & $8(7.7)$ & \\
\hline Emergency department 2 & $20(8.1)$ & $10(9.6)$ & \\
\hline Surgery department (men) & $10(4.1)$ & $8(7.7)$ & \\
\hline Surgery department (women) & $11(4.5)$ & $6(5.8)$ & \\
\hline Orthopedic department (men) & $25(10.2)$ & $6(5.8)$ & \\
\hline Orthopedic department(women) & $12(4.9)$ & $7(6.7)$ & \\
\hline Surgery room & $30(12.2)$ & $15(14.4)$ & \\
\hline Intensive Care Unit & $37(15.0)$ & $12(11.5)$ & \\
\hline Clinic & $22(8.9)$ & $15(14.4)$ & \\
\hline Neurology department & $22(8.9)$ & $6(5.8)$ & \\
\hline Nursing Office & $10(4.1)$ & $3(2.9)$ & \\
\hline Neurosurgery department & $25(10.2)$ & $8(7.7)$ & \\
\hline
\end{tabular}


ers believe that physical factors only partially explain the high prevalence of low back pain, and psychosocial factors in the work environment cannot be ignored (16). This study was performed on 350 nurses; a high percentage of them were female unlike Bejia et al (17) investigation that more subjects were male. This can be related to this fact that women constitute a large portion of the nursing profession in Iran. There was not a significant relationship between gender and back pain. This finding is similar to the study of Yip (7). Several studies have also found that gender cannot increase the risk of low back pain (18-21). Nearly $50 \%$ of the nursing staff performed an exercise that led to no significant result. Regular physical activities, due to strengthening the back muscles, reduce the chances of low back pain. But there are studies that acknowledge the ineffectiveness of exercise in reducing the incidence of low back pain $(18,22,23)$. A significant correlation was found between smoking and the incidence of low back pain. Although the poor consequence of smoking is known in the incidence of low back pain, but the results of some studies indicate the effect of smoking on the risk of low back pain (7). There was a significant relationship between BMI and history of low back pain. This was consistent with the results of another study on the effect of BMI in low back pain (24). $48.3 \%$ of patients had no child, and $26.3 \%$ had only 1 child. Also, regarding the number of pregnancies, $50.9 \%$ had no history of pregnancy and $25 \%$ had 1 pregnancy. In this regard, the pregnancy or number of children had no significant relationship with low back pain. Yip also found no significant relationship between low back pain and pregnancy (7). On the other hand some studies have confirmed the relationship between the number of pregnancies and deliveries with low back pain. This difference may be due to prenatal care, dissimilar physiological characteristics of women's bodies, and causes of back pain during pregnancy (25-27). Nurses' low back pain can reduce the quality of health care services and increase the dissatisfaction of patients as a result. In order to increase the level of patient satisfaction with nursing services, physical activity, diet modification, and weight loss are recommended. Also, the establishment of training classes can be somewhat effective in order to control biomechanical factors of low back pain. So, conducting studies addressing biomechanical factors involved in low back pain is recommended. In future research, determining the amount of cost due to the absence of staff and its reflection in the care of patients is suggested.

\section{Conclusion}

The results of this study showed a prevalence of $70 \%$ regarding low back pain among nurses working in Poursina hospital in Rasht in Gilan. Age, BMI, and physical activity were significantly associated with the prevalence of low back pain. In addition, no relationship between gender, occupation, marital status, smoking, family history, frequency of lifting heavy things, work experience, and workplace with back pain was found.

\section{Acknowledgments}

We would like to declare our sincere appreciation to all nursing staff of Poursina hospital in Rasht for their cooperation in this study.

\section{Ethical issues}

This study was approved by the ethics committee of Gilan University of Medical Sciences. During the study, researchers also were committed to the principles of the Helsinki Declaration on the protection of patient confidentiality.

\section{Authors' contributions}

All authors met four criteria for authorship contribution based on recommendations of the International Committee of Medical Journal Editors.

\section{References}

1. Manek NJ, MacGregor A. Epidemiology of back disorders: prevalence, risk factors, and prognosis. Curr Opin Rheumatol 2005; 17(2):134-40.

2. Furlan AD, Brosseau L, Imamura M, Irvin E. Massage for low-back pain: a systematic review within the framework of the Cochrane Collaboration Back Review Group. Spine 2002; 27(17): 1896-910. doi: 10.1097/00007632-200209010-00017.

3. Andersson GB. Epidemiological features of chronic low-back pain. Lancet 1999; 354(9178): 581-5. doi: 10.1016/s0140-6736(99)01312-4.

4. Floren AE. Occupational Medicine Practice Guidelines, Evaluation and Management of Common Health Problems and Functional Recovery in Workers. ACEOM; 1997.

5. Forouzanfar MM, Alitaleshi H, Hashemi B, Baratloo A, Motamedi M, Majidi A, et al. Emergency nurses 'job satisfaction and its determinants. Journal of Shahid Beheshti School of Nursing \& Midwifery. 2013; 23(80): 10-4. [In Persian].

6. Maul I, Läubli T, Klipstein A, Krueger H. Course of low back pain among nurses: a longitudinal study across eight years. Occup Environ Med 2003; 60(7): 497-503. doi: 10.1136/oem.60.7.497.

7. Yip VY. New low back pain in nurses: work activities, work stress and sedentary lifestyle. J Adv Nurs 2004; 46(4): 430-40. doi: 10.1111/j.1365-2648.2004.03009.x.

8. Cunningham LS, Kelsey JL. Epidemiology of musculoskeletal impairments and associated disability. Am J Public Health 1984; 74(6): 574-9. doi: 10.2105/ajph.74.6.574.

9. Blue CL. Preventing back injury among nurses. Orthop Nurs 1996; 15(6): 9-20. doi: 10.1097/00006416199611000-00009.

10. Sheehan JP. If you injure your back on the job. RN 1999; 62(8): 63-6.

11. Leggat PA, Kedjarune U, Smith DR. Occupational 
health problems in modern dentistry: a review. Ind Healt 2007; 45(5): 611-21. doi: 10.2486/ indhealth.45.611.

12. Lindfors P, Von Thiele U, Lundberg U. Work characteristics and upper extremity disorders in female dental health workers. J Occup Health 2006; 48(3): 192-7. doi: 10.1539/joh.48.192.

13. Chowanadisai S, Kukiattrakoon B, Yapong B, Kedjarune U, Leggat PA. Occupational health problems of dentists in southern Thailand. Int Dent J 2000; 50(1): 36-40. doi: 10.1111/j.1875-595x.2000. tb00544.x.

14. Marshall ED, Duncombe LM, Robinson RQ, Kilbreath SL. Musculoskeletal symptoms in new south wales dentists. Aust Dent J 1997; 42(4): 240-6.

15. Oleinick A, Gluck JV, Guire KE. Factors affecting first return to work following a compensable occupational back injury. Am J Ind Med 1996; 30(5): 540-55.

16. Ramazani Badr F, Nikbakht A, Mohammadpour A. Low-back pain prevalence and its risk factors in nurses. Iranian Journal of Nursing Research 2006; 1(2): 37-42. [In Persian].

17. Bejia I, Younes M, Jamila HB, Khalfallah T, Salem KB, Touzi M, et al. Prevalence and factors associated to low back pain among hospital staff. Joint Bone Spine 2005; 72(3): 254-9. doi: 10.1016/j.jbspin.2004.06.001.

18. Violante FS, Fiori M, Fiorentini C, Risi A, Garagnani G, Bonfiglioli R, et al. Associations of psychosocial and individual factors with three different categories of back disorder among nursing staff. J Occup Health 2004; 46(2): 100-8. doi: 10.1539/joh.46.100.

19. Smedley J, Egger P, Cooper C, Coggon D. Manual handling activities and risk of low back pain in nurses. Occup Environ Med 1995; 52(3): 160-3. doi: 10.1136/ oem.52.3.160.

20. Lorusso A, Bruno S, Labbate N. A review of low back pain and musculoskeletal disorders among Italian nursing personnel. Ind Health 2007; 45(5): 637-44. doi: 10.2486/indhealth.45.637.

21. Marena C, Gervino D, Pistorio A, Azzaretti S, Chiesa P, Lodola L, et al. Epidemiologic study on the prevalence of low back pain in health personnel exposed to manual handling tasks. G Ital Med Lav Ergon 1997; 19(3): 89-95. [In Italian]

22. Mandel JH, Lohman W. Low back pain in nurses: the relative importance of medical history, work factors, exercise, and demographics. Res Nurs Health 1987; 10(3): 165-70. doi: 10.1002/nur.4770100308.

23. Martinelli S, Artioli G, Vinceti M, Bergomi M, Bussolanti N, Camellini R, et al. Low back pain risk in nurses and its prevention. Prof Inferm 2004; 57(4): 238-42. [In Italian].

24. Stubbs DA, Buckle PW, Hudson MP, Rivers PM, Worringham CJ. Back pain in the nursing profession. I. Epidemiology and pilot methodology. Ergonomics 1983; 26(8): 755-65.

25. Ostgaard H, Andersson G, Karlsson K. Prevalence of back pain in pregnancy. Spine 1991; 16(5): 549-52.

26. Von Korff M, Saunders K. The course of back pain in primary care. Spine 1996; 21(24): 2833-7.

27. Worku Z. Prevalence of low-back pain in Lesotho mothers. J Manipulative Physiol Ther 2000; 23(3): 147-54. 